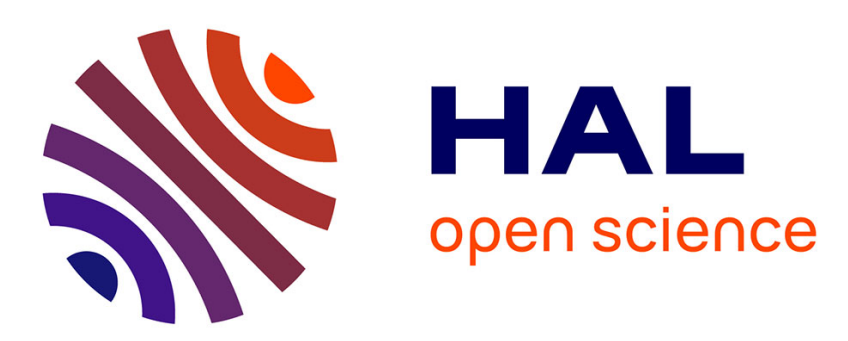

\title{
Changes in the starch-protein interface depending on common wheat grain hardness revealed using atomic force microscopy
}

Emna Chichti, Matthieu George, Jean-Yves Delenne, Valerie Lullien-Pellerin

\section{- To cite this version:}

Emna Chichti, Matthieu George, Jean-Yves Delenne, Valerie Lullien-Pellerin. Changes in the starchprotein interface depending on common wheat grain hardness revealed using atomic force microscopy. Plant Science, 2015, 239, pp.1-8. 10.1016/j.plantsci.2015.07.006 . hal-01238105

\section{HAL Id: hal-01238105 \\ https://hal.science/hal-01238105}

Submitted on 4 Dec 2015

HAL is a multi-disciplinary open access archive for the deposit and dissemination of scientific research documents, whether they are published or not. The documents may come from teaching and research institutions in France or abroad, or from public or private research centers.
L'archive ouverte pluridisciplinaire HAL, est destinée au dépôt et à la diffusion de documents scientifiques de niveau recherche, publiés ou non, émanant des établissements d'enseignement et de recherche français ou étrangers, des laboratoires publics ou privés. 


\section{Accepted Manuscript}

Title: Changes in the starch-protein interface depending on common wheat grain hardness revealed using Atomic Force Microscopy

Author: Emna Chichti Matthieu George Jean-Yves Delenne Valérie Lullien-Pellerin

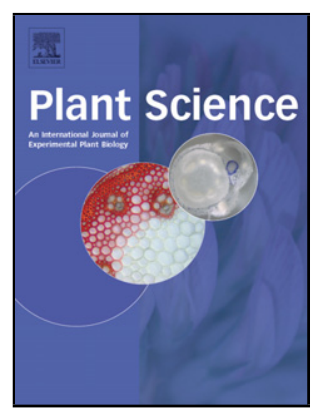

PII: S0168-9452(15)30012-1

DOI:

Reference: http://dx.doi.org/doi:10.1016/j.plantsci.2015.07.006

PSL 9232

To appear in: $\quad$ Plant Science

Received date: 6-5-2015

Revised date: 6-7-2015

Accepted date: $\quad$ 7-7-2015

Please cite this article as: Emna Chichti, Matthieu George, Jean-Yves Delenne, Valérie Lullien-Pellerin, Changes in the starch-protein interface depending on common wheat grain hardness revealed using Atomic Force Microscopy, Plant Science http://dx.doi.org/10.1016/j.plantsci.2015.07.006

This is a PDF file of an unedited manuscript that has been accepted for publication. As a service to our customers we are providing this early version of the manuscript. The manuscript will undergo copyediting, typesetting, and review of the resulting proof before it is published in its final form. Please note that during the production process errors may be discovered which could affect the content, and all legal disclaimers that apply to the journal pertain. 


\section{Changes in the starch-protein interface depending on common wheat grain}

hardness revealed using Atomic Force Microscopy

EmnaChichti $^{\mathrm{a} 1}$, Matthieu George ${ }^{\mathrm{b}}$, Jean Yves Delenne $^{\mathrm{a}}$, Valérie Lullien-Pellerin ${ }^{\mathrm{a}}$

${ }^{a}$ INRA, UMR 1208, Ingénierie des Agropolymères et Technologies Emergentes, 2

Place Viala, 34060 Montpellier Cedex 02, France,chichti@supagro.inra.fr, delenne@supagro.inra.fr

'Institut Charles Coulomb, UMR 5221, CNRS-UM2, Place Eugène Bataillon, 34095

Montpellier Cedex, France,mgeorge@univ-montp2.fr

Correspondingauthor: Lullien-Pellerin V. UMR IATE, 2 Place Viala, 34060

Montpellier Cedex 02, France. Tél : 33 (0) 4996131 05, Fax : 33 (0) 499613076.

E-mail : lullien@supagro.inra.fr

${ }^{1}$ Present adress UMR 95 QualiSud, TA B95/16, 73 rue Jean-François Breton, 34398

Montpellier Cedex 5, France.

Graphical abstract 


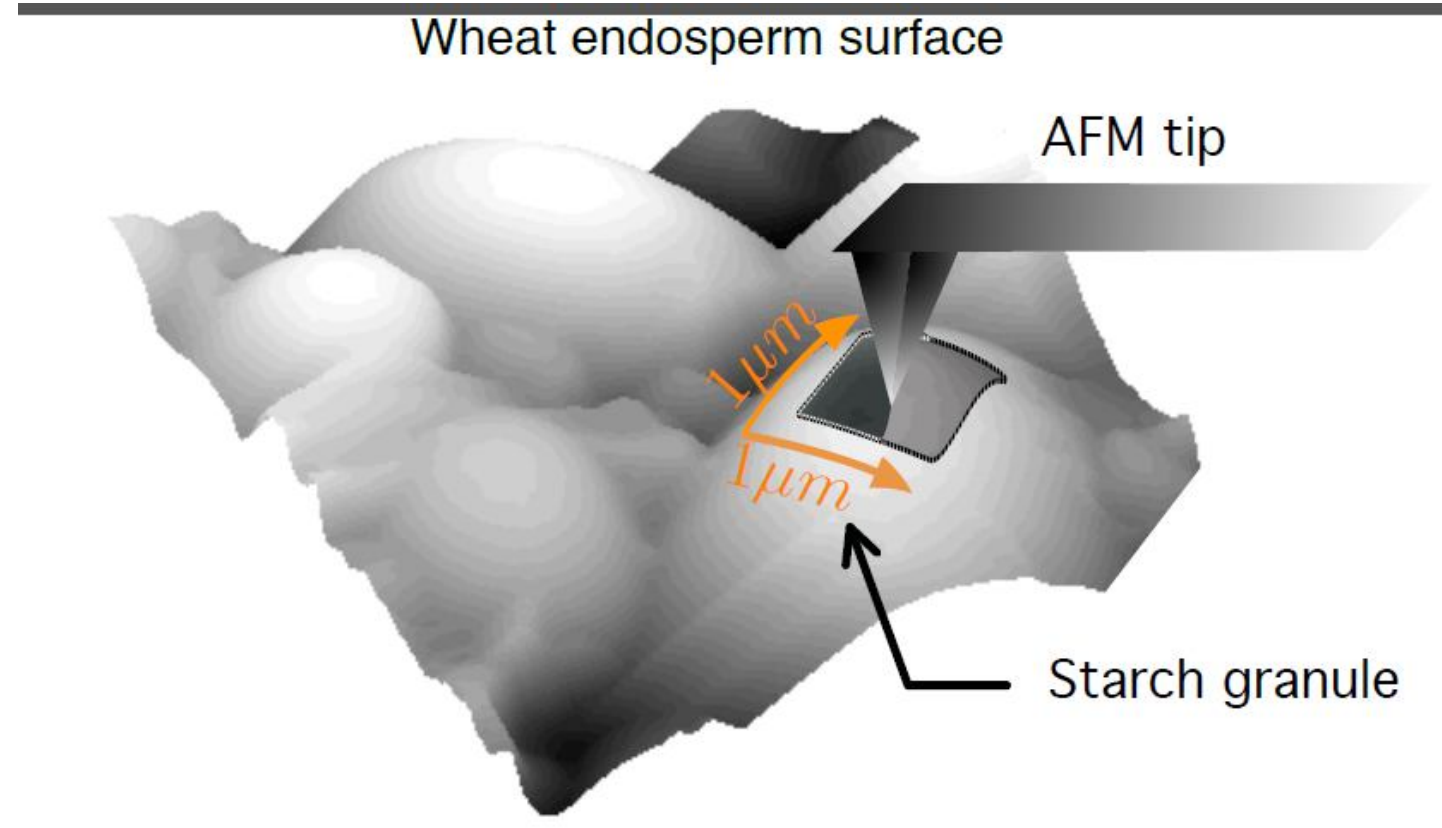

\title{
HIGHLIGHTS
}

- Exploresthe starch surface by nano-scratch AFM in the wheat grain endosperm

- Shows differences in mechanical properties related withgrain hardness

- Relates the differences to distinctpuroindoline $b$ allele with near-isogenic lines

- Demonstrates for the first time an effect of puroindolines in grain mechanics

- Identifies a potential lubricant interface between starchand gluten in soft grains

\begin{abstract}
TheAtomic Force Microscopetip was used to progressivelyabradethe surface of noncutstarch granules embedded in the endosperm protein matrix in grain sections from wheat near-isogenic lines differing in the puroindoline $\mathrm{b}$ geneand thus hardness. In the hard near-isogenic wheat lines, starch granulesexhibitedtwo distinctprofilescorresponding either toabrasion in the surrounding protein layer or the starch granule. An additional profile,only identified in soft lines, revealed a marked stop in the abrasionat the protein-starch transitionsimilar to a lipid interface playing a lubricant role. Itwas relatedto the presence of both wild-type puroindolines,already
\end{abstract}


suggested to act at the starch-protein interface through their association with polar lipids.

This study revealed, for the first time, in situdifferences in the nano-mechanical properties at the starch-protein interfacein the endosperm of wheat grainsdepending on the puroindoline allelic status.

Abbreviations: (AFM), atomic force microscopy; $\left(\mathrm{A}_{\mathrm{T}}\right)$,projected frontal abrasion area; (ESEM), Environmental Scanning Electron Microscopy; $\left(\mathrm{F}_{\mathrm{N})}\right.$, normal force; $\left(\mathrm{F}_{\mathrm{T}}\right)$, tangential force; $(\mathrm{H})$, polymer hardness value; $(\mathrm{PIN})$, puroindoline; $(\mathrm{N})$, number of abrasive scans; $\left(\mathrm{n}_{1}\right)$, number of AFM tip scan lines; (NILs), near isogenic lines; $(\mathrm{R})$, tip radius; $(\mathrm{V})$, abraded volume; $\left(\mathrm{V}_{\mathrm{T}}\right)$, tip velocity; $(\mathrm{z})$, abrasion depth; $\left(\mathrm{z}_{\mathrm{norm}}\right)$, normalized depth. 
Keywords: endosperm; nanomechanics; microstructure; puroindoline; T. aestivum 


\section{INTRODUCTION}

The major part of common wheat (TriticumaestivumL.) grains corresponds to the starchy endosperm (80-85\% of the dry grain mass) and is composed of cells filled with at least two distinct size populations of starch granules, between 8 and $30 \mu \mathrm{m}$, embedded in a protein matrix, mainly composed of storage proteins able to form the so-called gluten network[1]. Changes in the interface between the endosperm composing polymers are now recognized as the major factor to explain distinct hardness wheat classes[2,3]. It was found to be related to differences in the amount and allelic form, at the starch granule surface[4], of basic low-molecular weight cystein rich proteins carrying a unique tryptophan domain[5], called Puroindolinea(PINA) and Puroindolineb(PINB), whose corresponding genes were found to be located within the main genetic locus $(\mathrm{Ha})$ controlling hardness in the short arm of chromosome 5D[6-8]. Expression of the wild-type alleles PinaDlaandPinb-Dla, encoding PINA and PINB respectively, was found to lead to a soft mechanical behavior whereas mutation or deletion in one or both of the PINencoding genes results in a harder grain texture[9]. In Europe and North America, the most common mutation in PINB is encoded by the gene allele Pinb-DIband corresponds to a single amino acid change (Gly46Ser), which leads to a hard grain phenotype[10$12]$.

These differences in grain mechanical resistance has a main impact on the wheat grain end-use properties as it plays a role in the energy required for starchy endosperm isolation duringprocessing, in the obtained particle sizes and final flour yield, as well as in starch granule dissociation from the protein matrix or starch granule damage[13-17]. More recently, construction of a numerical model mimicking the endosperm granular structure showed that lowering the adhesion 
strength between starch granules and the protein network leads to a decrease of the starch damage as observed in soft grains[18,19].

If differences in a soft and a hard grain phenotype have been clearly linked to the presence of both of the wild-type PIN genes thanks to the use of near-isogenic lines (NIL)[20,21] and complementation of null[22] or mutated alleles[23], introduction of PIN genesin other cereals, such as durum wheat[24], rice[25] or corn[26] lacking the corresponding genes, was moreover found to reduce grain hardness. In addition, RNAi-mediated silencing of one of the PIN genes was shown to decrease the expression of the others and led to a significant increase of grain hardness[27]. However, the mechanismsby which PINs impact on the grain texture and have a role in the starch protein interface remain unclear.

The main hypothesissuggeststhat interactionof PINs with the starch granule surface is mediated by polar lipids from the remnant amyloplasts [28]. This hypothesis is supported by the differences in polar (phospho- and glyco-) lipid amount found associated with starch depending on PIN composition[29-31]and by in vitrodemonstration of the tight bonding of PINs withpolar lipids[32], as well as possibleinsertion into the lipid bilayer[33,34]. PINs are thus believed to impair starch-protein adhesion via their lipid interaction and thus affect grain hardness, but evidence of mechanical changes at the starch granule interface was still missing.Probing the starch granule interface in the wheat endosperm from nearisogenic lines differing in hardness thus appears interesting to study to better understand the differences in the interactions between the main endosperm polymers. As a method to investigate both the local structure and mechanical properties[35,36], Atomic Force Microscopy (AFM) appears appropriate to investigate the endosperm structure and hardness properties. Indeed it was used to reveal imagingdifferences 
between hard and soft endosperm structure [37]but no mechanical studies were pursued. Recently, using an AFM tip as an abrasive tool to abrade the surface of tablets made of starch or the storage protein matrix isolated from wheat grains, distinct mechanical properties of the two main endosperm components were determined and revealed relatively high respective hardness values of around 2.4 and $0.6 \mathrm{GPa}$ [38].Therefore,this original AFM method which proceeds by scratching of the surface layer-by-layer appeared the most appropriate to both explore the wheat endosperm polymer properties in situandinvestigate the starch granule interface with the surrounding protein matrix. 


\section{MATERIALS AND METHODS}

\subsection{Plant material and growth conditions}

NIL of Triticumaestivum L. displaying either a or b allelic forms of Pinb-D1 encoding the wild-type or mutated (Gly46Ser) PINB protein,respectively, and thus differing in grain hardness were described previously[39]. Genetic similarity (> 97 $\%$ ) between the NILs was confirmed with the use of Diversity Array Technology markers[40]generated by Triticarte Pty.Ltd (www.triticarte.com.au). Grains were harvested in summer 2008, cleaned to remove broken kernels andimpurities, and then stored at $4^{\circ} \mathrm{C}$ before analysis. Grain hardness was evaluated using a Percon NIRS apparatus (method 39-70A [41])on randomly chosen grain sub-samples of each near-isogenic line and results wererespectively equal to 17 for soft NIL (PinaDla/PinbDla genotype) and 63 for hard NIL (Pina-Dla/PinbD1b genotype).

\subsection{Sample preparation for microscopy}

Wheat grain sections were obtained with a cryotome (Microm HM 520 Cryostat, Thermo Scientific, USA). Grains were picked up randomly in the grain population of each near-isogenic line and cut at both ends to eliminate the germ and the brush then glued on a sample holder using a Frozen Section Medium (Neg-50, Richard-Allan Scientific, Thermo Scientific, USA). The grains were fixed from the widest part corresponding to the germ and placed into the cryotome at $-28^{\circ} \mathrm{C}$ before sectioning, until the glue was frozen $(2 \mathrm{~min})$. Sections of $50 \mu \mathrm{m}$ were removed progressively to reach the middle of the grain. Then continuous cutting of the sample surface was performed by removing thinner sections of $5 \mu \mathrm{m}$. The remaining $500 \mu \mathrm{m}$ grain sections were finally fixed on glass slides, protected with parafilm and kept under 
controlled temperature and humidity conditions $\left(20^{\circ} \mathrm{C}, 30 \%\right.$ relative humidity) before microscopy analysis.

\subsection{Environmental Scanning Electron Microscopy (ESEM) and AFM}

\section{Microscopy}

ESEM (Fei Quanta 200 FEG, FEI Co, Hillsboro, OR, USA) without sputter coating was used for grain section imaging.

AFM assays were performed as previously described[38]with a Nanoscope V atomic force microscope (Bruker instruments, Santa-Barbara, CAUSA), operating in the contact mode under controlled conditions of temperature and humidity $\left(20^{\circ} \mathrm{C}, 30 \%\right.$ relative humidity). Commercial silicontips (Ref. FMV, 2.8N/m, Bruker, Camarillo, CA, USA) mounted on a rectangular cantilever with stiffness ranging between 1 and $5 \mathrm{~N} / \mathrm{m}$ were chosen to preserve reasonable measurement sensitivity and to exert sufficiently large forces to abrade the samples. Before each measurement, the normal $\left(\mathrm{F}_{\mathrm{N}}\right)$ and tangential forces $\left(\mathrm{F}_{\mathrm{T}}\right)$ were calibrated and the contacting areas of the tips werecharacterized before and after calibration and at the end of AFM measurements, as described previously[38]. The contacting areas of the tips were characterized through reverse imaging obtained with AFM on a calibrating grid of equally-spaced sharp points of apex radius around $10 \mathrm{~nm}$ (TGT01, Mikromasch, Inc., Estonia). These measurements clearly showed that the AFM tip apex can be well fitted after calibration by a sphere from the extremity to $20 \mathrm{~nm}$ high, with an average radius for the set of tips $\mathrm{R}=82 \pm 32 \mathrm{~nm}$. This value is significantly above the initial tip radius of $10 \mathrm{~nm}$ due to wear off occurring during the calibration process and was checked to remain stable during abrasion assays. 
AFM assays were performed on wheat grain sections after selection of a working area i.e at the surface of a small starch granule. A first topographic image $(5 \times 5 \mu \mathrm{m})$ was acquired at a low applied normal force $\left(\mathrm{F}_{\mathrm{N}}=100 \mathrm{nN}\right)$ and a scan tip velocity $\mathrm{V}_{\mathrm{T}}=$ $10 \mu \mathrm{m} / \mathrm{s}(512 \times 512$ pixels $)$ and was used as the reference of the undamaged surface. The abrasion process was then initiated in the central area $(\mathrm{L} \times \mathrm{L}=1 \times 1 \mu \mathrm{m})$ with an increase of the applied normal force $\left(\mathrm{F}_{\mathrm{N}}>200 \mathrm{nN}\right)$ and a decrease of the scan velocity $\mathrm{V}_{\mathrm{T}}=2 \mu \mathrm{m} / \mathrm{s}(256 \times 256$ pixels $)$. Both the trace and retrace $\mathrm{F}_{\mathrm{T}}$ force maps were acquired (respectively scanning from left side to right side of the image and from right side to left side) to determine the average force sustained by the sample in the direction of displacement. Then, the normal force was lowered back to its initial value $(100 \mathrm{nN})$ and a second topographic image $(5 \times 5 \mu \mathrm{m})$ was recorded at $\mathrm{V}_{\mathrm{T}}=10 \mu \mathrm{m} / \mathrm{s}$ before again increasing the normal force to further abrade the material. A progressive and controlled abrasion of the sample was ensured by repeating the abrasion step at least twenty times with a mean number of abrasion scans $\mathrm{N}=50$, depending on the abraded area, interrupted by regular acquisitions of larger topographic images. Large topographic images $(5 \mathrm{x} 5 \mu \mathrm{m})$ were acquired after each scan until five scans were reached and then after each group of five scans. Repetitions of the abrasion process were made on different starch granules (at least twelve) chosen in the middle of the grain cheek section from randomly selected soft or hard NIL samples. The acquired AFM images were visualized and analyzed using the Gwyddion 2.26 software (Department of Nanometrology, Czech Metrology Institute, Brno, CZ) in order to evaluate the abrasion depth and the friction force $\mathrm{F}_{\mathrm{T}}$. The depth increment between two successive abrasion steps was obtained by subtracting the two corresponding topographic images after careful lateral positioning through correlation techniques and sensible leveling of the height to 
account for instrumental drift. The evolution of abrasion depth was then determined by summing all depth increments. More details on the measurement protocol and the error estimations can be found in Chichti et al [38].

\subsection{Statistical analysis}

Analysis of variance was performed with the XLSTAT software (2008 version, Addinsoft, Paris) using the Tukey test at $5 \%$ probability for significance between differences. 


\section{RESULTS}

\subsection{Microstructure analysis of the grain endosperm depending on hardness}

Microstructure of the starchy endosperm from cryo-cut near-isogenic wheat grains differing inhardness was either observed using ESEM or AFM (Fig. 1). Both types of observation highlighted clear differences in grain endosperm microstructure according to wheat hardness. Endosperm from soft grains (Pina-Dla-Pinb-Dla genotype) was shown to display a loose structure (Fig. 1A) in comparison with hard grains (Pina-Dla-Pinb-Dlb), which presented amore tightly compacted endosperm with microcracks bypassing the starch granules (Fig. 1B). Differences were more pronounced using AFM, and at a lower scale $(10$ versus $50 \mu \mathrm{m})$, where the endosperm from soft grains was found to present more uncut starch granules (Fig. 1C). Starch granules also appeared less embedded in the protein matrix and even dislodged from the protein matrix in comparison with the endosperm structure from hard grains where the sectioningentailedcutting of the major part of the large starch granules and some of the small ones, depending on their position in the endosperm(Fig. 1D).

\section{Figure 1}

Therefore, only small starch granuleswhich were observed as undoubtedly uncut in AFM topographic images (mean diameter around $5 \mu \mathrm{m}$ ), wereselected, as shown in Fig. 1E,to explore the starch-protein interface. As revealed in Fig. 1F, the AFM topographic image did not allow the identification ofthe polymer nature at the surface of the selected starch granule. 


\subsection{Probing of the polymer present at the starch granule surface duringendosperm abrasion}

A square of $\mathrm{L} \times \mathrm{L}=1 \times 1 \mu \mathrm{m}(\mathrm{Fig} .1 \mathrm{~F})$ was selected in the middle of each small starch granule in order to avoid the curvature and border effect. Its surface was abraded using an AFM tip according to the conditions recently described[38]. According to these conditions, the abrasion process could be interpreted as a linear scratching test to evaluate the resistance of the analysed material. As already described in Chichti et al.[38], atribological model was developed, to assess the material hardness which is related to the normal applied force $\mathrm{F}_{\mathrm{N}}$ and the depth of the abraded area $\mathrm{z}$. The projected frontal area in contact with the AFM tip, $\mathrm{A}_{\mathrm{T}}$, corresponds to the surface of the removed material obtained for each scratching line andcan be determined from the equation of removed volume, taking into account the total depth $\mathrm{z}$, the length of the abraded scan $\mathrm{L}$, the number of abrasion scans $\mathrm{N}(20<\mathrm{N}<70)$ and $\mathrm{n}_{1}$ the number of scan lines in the acquired image (256 lines):

$$
A_{T}=\frac{V}{2 n_{l} N L}=\frac{z L}{2 n_{l} N} \text { Eq. } 1
$$

Considering the definition of hardness (ratio between the applied normal force and the area under the tip) and assuminga spherical approximation of the tip apex, we get that $A_{T}$ is also a function of the applied normal force $F_{N}$, the tip radius $R$ and the hardness $\mathrm{H}$ of the abraded material:

$$
A_{T}=\frac{F_{N}^{3 / 2}}{2 R(\pi H)^{3 / 2}} \text { Eq. } 2
$$

According to equations 1 and 2, the depth of the scratched area $\mathrm{z}$ should increase linearly with the scan number $\mathrm{N}$ when abrasion occursin a homogeneous material, at a given applied force $\mathrm{F}_{\mathrm{N}}$ and for a determined tip radius $\mathrm{R}$. As AFM assays were performed at different applied forces $\mathrm{F}_{\mathrm{N}}$ and with different $\mathrm{AFM}$ tips to explore potential differences in polymer hardness and to avoid tip wear, the depth $\mathrm{z}$ was 
normalized $\left(\mathrm{z}_{\text {norm }}\right)$ according to $\mathrm{F}_{\mathrm{N}}$ and $\mathrm{R}$ for comparison between distinct abraded areas:

$$
z_{\text {norm }}=\frac{z R}{F_{N}^{3 / 2}}=\alpha N \text { Eq. } 3
$$

Changes in the normalized depth $\mathrm{z}_{\mathrm{norm}}$ as a function of the abrasive scan numbers $\mathrm{N}$ was thus relevant to characterize the different polymer layers which can be encountered during the progressive abrasion of the heterogeneous endosperm microstructure.

In a homogeneous material, the slope $\alpha$ describing the linear variation between the normalized $\mathrm{z}_{\text {norm }}$ and the number of abrasive scan $\mathrm{N}$ could be considered as a direct indication of the material hardness $\mathrm{H}$ since the dimension of the abraded area $\mathrm{L}$ and the number of scan line $n_{1}$ were kept constant in all of themeasurements:

$$
\alpha=\frac{n_{l}}{L(\pi H)^{3 / 2}} \text { Eq. } 4
$$

This slope will be used to identify the nature of the polymers encountered duringprogressive abrasion at the starch surface. According to the previously determined hardness of the endosperm constitutive polymers[38], reported in Table 1 , values for the curve slope awere expected to be equal to $0.012 \pm 0.005 \mathrm{~nm}^{2} / \mathrm{nN}^{3 / 2}$ and $0.09 \pm 0.04 \mathrm{~nm}^{2} / \mathrm{nN}^{3 / 2}$ forstarch and protein network, respectively, in our working conditions.

\section{Table 1}

\subsection{AFM abrasion at the starch surface in the endosperm of hard wheat grain sections}

Distinct areas selected in apparent uncut starch granulesurfaces were scratched using the AFM tip in the endosperm of grains from thehard NILdisplaying the Pina- 
Dla/Pinb-D1b genotype. Evolution of the normalized depth $\mathrm{z}_{\text {norm }}$ as a function of the number of abrasive scans $\mathrm{N}$ revealed two distinct types of abrasion profiles summarized in Fig. 2 depending on the analysed starch granule.

In one out of three AFM scratching assays, a constant linear progression of the normalized depth according to $\mathrm{N}$ was observed consistent with the removal of a homogeneous material (Fig. 2A). Considering the curve slope $\alpha(\alpha=0.013$ $\mathrm{nm}^{2} / \mathrm{nN}^{3 / 2}$ as an example in Fig. $2 \mathrm{~A}$ ), the abraded material canbe considered as starch polymerin accordancewithits previously determined hardness value[38].The considered abraded area thus appeared to correspond tothe naked starch granule.

\section{Figure 2}

Normalized depth according to the number of AFM tip scans at the surface of other analysedstarch granules in the endosperm of hard grainswasfound to present nonlinear curvescharacterized by a progressive transition from a linear regime with a high slope $\alpha\left(\alpha=0.05 \mathrm{~nm}^{2} / \mathrm{nN}^{3 / 2}\right.$ as forexample in Fig. $\left.2 \mathrm{~B}\right)$, consistent with that calculated with protein hardness, to another linear regime with a lower slope $(\alpha=$ $0.009 \mathrm{~nm}^{2} / \mathrm{nN}^{3 / 2}$ ) corresponding to the expected slope for starch polymer (Fig. 2B). Indeed as the mechanical resistance of protein polymer is lower than starch it was more easielyremoved with a lower number of AFM tip scans in comparison with the starch polymer. This material heterogeneityrevealed that AFM abrasion in these cases occuredat a starch granule covered with a protein layer. Mean thickness of this protein layer was estimated to be in the order of a hundred nanometers, ranging from 48 to $188 \mathrm{~nm}$, depending on the selected starch granule. 
The hardness $\mathrm{H}$ was determined with equation 4 using the slopes $\alpha$ of each linear part of the curve for each abraded area and compared,in Fig. 3,to hardness values previously determined in similar AFM conditions on tablets made of isolated starch and protein polymers[38]. Taking into account the uncertainty of our measurements (calculated and represented by bar errors in Fig. 3), hardness values obtained for starch and protein from assays with hard wheat grain sections were in good agreement with hardness values obtained on isolated biopolymers whatever the applied normal force used in the AFM assays. However, in afewcases, determined hardness values appeared outside the range of the data corresponding to the extracted polymers and were found between those of theprotein matrix and starch.

\section{Figure 3}

Comparison of protein and starch hardness mean values and relative errors calculated with data obtained fromendosperm samples of hard wheat grains were summarized in Table 1 and showed no significantdifferences with the values determined with isolated polymers.

\subsection{AFM abrasion at the starch surface in the endosperm of soft wheat grain sections}

Distinct starch granules were abraded with the AFM scratching method in endosperm from soft near-isogenic grains carrying bothwild-typePIN genes PinaDla and Pinb-Dla. Results are expressed as described before and compared with those obtained in endosperm from NIL carrying the mutated allele encoding PINB. In half of the AFM assays, the obtained curves of normalized depth as a function of 
the number of abrasion scan presented a linear curve corresponding to purestarch as pointed out in Fig. 2A, whereas around a quarter displayed an abrasion profile, similar to thatobserved inFig. $2 \mathrm{~B}$, consistent with a starch granule covered with a protein layer.

Interestingly, a distinct abrasion profile, not previously observed in the endosperm from hard wheat grains, was revealed in four of the abraded areas and reported in Fig. 4A. In this case, abrasion started withthe removal of a proteinpolymer and ended by digging into the starch granule as determined by the corresponding values of respective curve slopes $\alpha$. But, a marked transition between the two parts of the profile, characterized by a "stop" of the AFM tip abrasion, was observed. Indeed, for up to twenty abrasion scans, normalized depth remained fairly constant and thus no material removal could bemeasured.

\section{Figure 4}

At this non-abrasive step, a significant drop of the lateral force $\mathrm{F}_{\mathrm{T}}$ was observed, as reported in Fig.4Bby the study of the $\mathrm{F}_{\mathrm{T}} / \mathrm{F}_{\mathrm{N}}$ ratio as a function of the abrasive scan number $\mathrm{N}$. Indeed, at this interface step, the $\mathrm{F}_{\mathrm{T}} / \mathrm{F}_{\mathrm{N}}$ ratio was found to be close to the friction coefficient while imagingthe sample topography and therefore confirmed the absence of abrasion. After a number of AFM tip scans without detectable abrasion, an increase in the $\mathrm{F}_{\mathrm{T}} / \mathrm{F}_{\mathrm{N}}$ ratio was observed, when abrasion was recovered and the starch polymer was beginning to be removed. No significant depth variation and thus no measurable volume of removed material were therefore possible at this interface step in comparison with those corresponding to protein or starch abrasion (inserts, Fig. 4A). However superficial damage of the scratched surface must have occured as 
further abrasion of the endosperm material could be continued.Depending on the selected scratching area, the mean thickness of the protein layer covering the starch surface was found to range from 7 to $40 \mathrm{~nm}$.

Hardness values of protein and starch obtained from the distinct scratched endosperm surface in soft NIL were also reported in Figure 3 and Table 1 and compared to values obtained from hard NIL and for isolated polymers. Results confirmed the higher mechanical resistance of wheat starch polymer in comparison with the endosperm protein network.Moreover, no significant differences were notedfor the polymers in wheat grains whatever their hardness, nor with the extracted polymers. 


\section{DISCUSSION}

The origin of the mechanical differences between soft and hard wheat grains was generally recognized to be linked to changes in the interactions between starch granules and the surrounding protein matrix in the endosperm and to be mediated by either the presence of both wild-typePINs or the mutation or deletion of one of them[28]. In this study, NILs carrying either the wild-type alleles Pina-Dla/PinbDla or the mutated version of the gene encoding PINB (Pina-Dla/Pinb-Dlb)were intentionally chosen to investigate the local differences between hard and soft endosperm.

ESEM, as well as AFM, observation of the starchy endosperm microstructure after grain cutting clearly confirmed the looser structure of the soft NIL in comparison with the hard, which displayed a more compact microstructure. Indeed, cutting in the endosperm from soft grains revealed local spaces in the protein matrix and possible sites of dislodged starch granules whereas starch granules in the endosperm from hard grains were firmly bound to the matrix and were more often cut, especially the large ones. Differences in cohesionbetween starch and the protein matrix were already pointed out in cultivated common wheat cultivars[42]andfurther clearly related to differences in PIN genotype by others[23,37,43,44]. It was also in accordance withthe attributed role of wild-type PINs as non sticking agents and correlates well with endosperm modelling which results in more starch damage when adhesion between starch granules and the protein matrix increased[18,19]. As a consequence only the interface between the non-cut small starch granules and the surrounding protein matrix could be explored,in soft and hard NIL grains, using an original AFM scratching method,previouslydescribed[38], and found to differenciate 
between the respective mechanical properties of wheat starch and the protein matrix (extracted as gluten).

Even if the number of AFM experiments on each type of NIL grains was necessarily low due to the time of data acquisition, between 12 and 20 independent starch granule surfaces were explored from each near-isogenic line, at different locations withinthe wheat endosperm and with distinct grains randomly selected. No differences between the mechanical properties ofthe two main endosperm polymers were measured in situwhatever the grain hardness,in accordance withprevious studies[2,38,45], clearly highlighting the importance oflocal investigationsofthe starch-protein interface. Indeed,distinct behaviorsat the starch surface were revealed between hard and soft NILs using an AFM tip as an abrasion tool.

In hard wheat grain sections, probed starch granule surfaces were mainly found covered with a protein layer of significant thickness $(48-188 \mathrm{~nm})$ whereas, in fewer cases,the AFM tip directly abraded the naked starch granule. When the starch granules were coated with the protein matrix, the abrasionprofile presented a gradual transition from the mechanical strength of proteins toward that of starch as abraded depth increased. This transition fits well with the traditionalarea-law-of-mixtures or volume-law-of-mixture models used to describe the mechanical hardness of a coated substrate[46-48]. When the adhesion between the coating and the substrate is strong enough, stresses aretherefore transferred from the coating to the substrate and the apparent hardness of the coated material is the average hardness of both materials weighted by the respective areas/volumes loaded in each of them. The mechanical reinforcement of the protein layer as the underneath starch sustains increasing strain by the AFM tip seems to fall well inside this frame and appears thus to indicate a sufficientadhesion at the protein/starch interface to allow for the stress/strain 
transfer.This law of mixtures could also explain the relative out of range values of a few protein or starch hardness data if obtained too close to the interface.In the endosperm from soft wheat grain sections, the surface of starch granules was mainly found naked revealing a non-cohesive interface with the protein network. Additionally, if in some positions, the starch granule was found to be covered witha protein layer,this layerwasthinner $(7-40 \mathrm{~nm})$ than that observed in the endosperm from hard NIL grains.Moreover, an additional abrasion profilenever observed in hard grainsanddisplaying a marked 'stop' of the AFM tip abrasion, along with a significant drop of the lateral forces, at the interface between starch and the surrounding protein matrix was observed. In this last case, the mechanical properties of both protein and starch were well defined within the expected hardness values and were not affected by the presence of the interface. This behaviorthus appears coherent with a lack of adhesion between the protein matrix and the starch granule at the interface and thus suggests that the protein network in this casewas not adhesively coupledwith the starch granule. Furthermore, the observed stronger resistance tothe tip abrasion concomitant with a drop of the lateral friction forces at the interface between the endosperm polymers appears to correlate well with the lubricating properties observed when exploring a non-puncturedpolar lipid covered surfaceusing AFM[49,50].Taking into account the genetic difference between soft and hard NILs, theseobserved distinct abrasion patterns at the surface of the starch granulecan be related to the PIN nature (wild-type versus mutant of PINB). The higher frequency for the observation of a naked starch surface in soft endosperm alsoconfirms the lower interaction between starch and the surrounding protein network andhigher decohesion of the starch granule with the protein matrix, already pointed out by ESEM or AFM imaging. Furthermore, a specific sliding interface was 
only found in soft grains in one out of four analyzed samples. Taking into account the number of samples analyzed with AFM in each near-isogenic lineand considering a similar frequencyto encounter such a sliding interface in both types of wheat grain, it is possible to estimate that the probability to find a specific mechanical behavior in one quarter of the samples from the soft line, but never for the samples from the hard line, is in the order of a few per cent. Therefore, even if the sampling appears small to perform a complete statistical analysis of the encountered abrasion behavior at the starch/protein interface, the observed rheological differences between starch and protein interface depending on hardness appear relevant and robust with a level of confidence higher than $95 \%$.Thus, it is the first time that significant mechanical differences at the protein-starch granule interface are experimentally evidenced.

As the peculiar sliding behaviorat the protein-starch interface was not observed in each of the explored positions in soft grains, it thus implies that changes in the PIN nature only impact in some places and not around the overall granule surface. This appears coherent with previous PIN detection at thestarch granule surface by immunolabelling[51], which clearly showed non-continuous location at the starch granule surface even if precise location and sub-cellular distribution in grains was not consensual[28].Unfortunatelly, AFM abrasion could not be coupled with immunolocalisation.

Most importantly, the peculiar abrasion profileonly observed at certain positions at the starch granule surface in the endosperm from soft NIL grains revealed a lipid interface between the protein matrix and the starch surface displaying a mechanical rolelikea lubricant. Taking into account the strong interactions with polar lipids pointed out for the wild-type PINs[32-34]and their suggestedmode of action at the starch surfacevia polar lipids[9,28], this observation appears particularly relevant. 
Indeed it is believed that wild-type PINs bind to remnant amyloplast polar lipids at the starch surface via their tryptophan-rich domain resulting in a soft mechanical behavior of the endosperm. However, the mechanismswerestill not identified.Our AFM observation unambiguously revealed possible mechanical differences at the starch granule surface mediated by lipids in the soft endosperm. As shown previously, a Glycine to Serine mutation at position 46 in PINB, next to the tryptophan rich domain,reducesits lipid-binding capacity[52], leadingto a lower amount of the deposited PINsat the starch granule surfaceand to a hardness increase in comparison with wheat grains containing the wild-type allele[4,53-55]. A higher association and stabilization of polar lipids around the starch granule with wild-type PINswas previously demonstrated[31] which could explainthe unique AFM abrasion profile found in soft NIL grains. However, it is difficult to determine if this unique profile observed in soft endosperm results from a higher amount of PINs linked to the starch granule in grains via a lipid stabilization or to the higher amount of polar lipids found at the starch surface when both wild-type PINs are present[30]. Indeed, recent experiments suggested that PINs need lipids for binding to the starch granule surface[56].

Thus, our AFM experiments highlighted for the first time, differences in mechanical properties at the starch granule surface depending on the PIN nature and consequently grain hardness. Observed abrasion profiles at the surface of starch granules in hard endosperm were in accordance with the suggested close association with the surrounding matrix as in the major part of the assays, starch granules were found to be covered with a thick protein layer even if cutting grain before AFM analysis could also lead to naked starch granules. By contrast, when wild-type PINs were present, a naked granule was preferentially found, as a loose interaction with 
the protein matrix. In some cases, identification of a lubricant interface highlights the possible mechanisms underneath the lower adhesion between the main wheat endosperm polymers found in soft NIL. A few assays also pointed out starch granule surface covered with a thinner protein layer in accordance with the fact that PINs were not uniformly distributed and more probably form patches at the starch surface[34,51]. However, if our AFM scratching method was found efficient to probe in situ polymer interfaces and explore the local mechanical properties, complementary studies will be necessary to better define the nature of the interactions and to more precisely identify the molecular partners. 


\section{ACKNOWLEDGMENTS}

We would like to thank F.-X Oury(Institut National de la RechercheAgronomique, UMR GénétiqueDiversitéetEcophysiologie des Céréales", Clermont-Ferrand) for providing the hard and soft NIL and for grain NIRS hardness measurements. We would also like to thank Jacques Escoute (Plate-formed'Histocytologie et d'ImagerieCellulairevégétale, CIRAD Montpellier) and the Montpellier RIO imaging platform for grain cryo-sectioning. We are also grateful to Montpellier 2 University and INRA (department Caractérisation et Elaboration des ProduitsIssus de l'Agriculture) for the $\mathrm{PhD}$ grant forE. Chichti and to A. Duri (UMR Ingénierie des Agropolymères et Technologies Emergentes, Montpellier) for her help to establish contact with the Institut Charles Coulomb. 


\section{REFERENCES}

[1]A.D. Evers,A.B. Blakeney, L. O’Brien,Cereal structure and composition, Aust. J. Agric. Res. 50 (1999) 629-650.

[2]K.K.Barlow,M.S. Buttrose,D.H. Simmonds,M.Vesk,The nature of starch-protein interface in wheat endosperm, Cereal Chem. 50 (1973) 443-454.

[3]D.H Simmonds,K.K.Barlow, C.W. Wrigley, The biochemical basis of grain hardness in wheat, Cereal Chem. 50 (1973)553-562.

[4]L.Day,D.G.Bhandari,P.Greenwell,S.A.Leonard,J.D. Schofield,Characterization of wheat puroindoline proteins, FEBS J. 273 (2006) 5358-5373.

[5]M.F. Gautier, M. Aleman, A.Guirao, D. Marion, J. Joudrier,Triticumaestivumpuroindolines, two basic cystein-rich seed proteins: cDNA sequence analysis and developmental gene expression, Plant Mol. Biol. 25 (1994) 43-57.

[6]N. Chantret, J. Salse, F. Sabot, S. Rahman, A. Bellec, B.Laubin,I. Dubois,C. Dossat, P. Sourdille, P. Joudrier, M.F. Gautier, L. Cattolico, M. Beckert, S. Aubourg, J. Weissenbach, M. Caboche, M. Bernard, P. Leroy, B. Chalhoub,Molecular basis of evolutionary events that shaped the hardness locus in diploid and polyploid wheat species (Triticum and Aegilops), Plant Cell. 17 (2005) 1033-1045.

[7]C.F.Morris,Puroindolines: the molecular genetic basis of wheat grain hardness, Plant Mol. Biol.48 (2002) 633-647.

[8] P. Sourdille,M.R. Perretant,G. Charmet, P. Leroy, M.F. Gautier,P. Jourdier, J.C. Nelson, M.E. Sorrells, M. Bernard,Linkage between RFLP markers and genes affecting kernel hardness in wheat,Theor. Appl. Genetics 93(1996) 580-586. 
[9]M. Bhave, C.J. Morris, Molecular genetics of puroindolines and related genes: regulation of expression, membrane binding properties and applications, Plant Mol. Biol. 66 (2008) 221-231.

[10]M.J. Giroux, C.F Morris, Wheat grain hardness results from highly conserved mutations in the friabilin components puroindolinea andb, Proc. Natl. Acad. Sci. 95 (1998)6262-6266.

[11]X.Q. Huang,M.S. Röder,Development of SNP assays for genotyping the puroindoline $\mathrm{b}$ gene for grain hardness in wheat using pyrosequencing, J. Agric. Food Chem. 53 (2005)2070-2075.

[12]C.F. Morris, M.Lillemo, M.C. Simeone, M.J. Giroux, S.L. Babb, K.K. Kidwell,Prevalence of puroindoline grain hardness genotypes among historically significant North American spring and winter wheats, Crop Sci. 41 (2001) 218-228.

[13]L. Feiz, J.M. Martin, M.J. Giroux,Relationship between wheat (Triticumaestivum L.) grains hardness and wet milling quality, Cereal Chem. 85(2008) 44-50.

[14]G. Igrejas, J.P.Martinant, A. Bouguennec,A.C. Villain, L. Saulnier, Y. Popineau, G. Branlard,Genetical, biochemical and technological parameters associated with biscuit quality. I. Prediction using grain hardness and water extractable arabinoxylans, J. Cereal Sci. 36 (2002) 115-124.

[15]C.F. Morris, S.P. Rose, Wheat, Chapter 1, in:R.J. Henry, P.S. Kettlewell (Eds),Cereal Grain Quality,Chapman \& Hall, London, 1996, pp. 3-54.

[16]I.Pasha,F.M. Anjum, C.F. Morris,Grain hardness: a major determinant of wheat quality, Food Sci. Technol. Int. 16 (2010) 511-522. 
[17]Y.Pomeranz, P.C. Williams, Wheat hardness: its genetic, structural and biochemical background, measurement and significance,in:Y. Pomeranz (Ed), Advances in Cereal Sciences and Technology,Vol X, American Association of Cereal Chemists, St Paul, Minnesota,1990, pp. 467-470.

[18]V. Topin, J.Y. Delenne, F. Radjai, L. Brendel, F. Mabille, Strength and failure of cemented granular material, Eur. Phys. J. E. 23 (2007)413-429.

[19]V. Topin, F. Radjai, J.Y.Delenne, F.Mabille, Mechanical modelling of wheat hardness and fragmentation, Powder Technol.190 (2009) 215-220.

[20]C.F.Morris, E. Garrison, G.E. King, R.E. Allan, M.C. Simeone,Identification and characterization of near-isogenic hard and soft hexaploid wheats, Crop Sci. 41 (2001) 211-217.

[21]D.E. Rogers, R.C. Hoseney, G.L. Lookhart, S.P. Curran, W.D.A Lin, R.G. Sears,Milling and cookie baking quality of near-isogenic lines of wheat differing in kernel hardness, Cereal Chem. 70 (1993)183-187.

[22]H.W. Wanjugi, A.C. Hogg, J.M. Martin, M.J. Giroux,The role of puroindoline A and B individually and in combination on grain hardness and starch association, Crop Sci. 47 (2007)67-76.

[23]B. Beecher, A. Bettge, E. Smidansky, M.J. Giroux,Expression of wild-type pinB sequence in transgenic wheat complements a hard phenotype,Theor. Appl. Genetics 105 (2002) 870-877.

[24]C.F. Morris, M.C.Simeone, G.E. King,D. Lafiandra,Transfer of soft kernel texture from Triticumaestivum to durum wheat, Triticumturgidum ssp. Durum, Crop Sci. 51 (2011)114-122. 
[25] K. Krishnamurthy, M.J. Giroux, Expression of wheat puroindoline genes in transgenic rice enhances grain softness, Nature Biotech. 19 (2001)162-166.

[26]J. Zhang, J.M. Martin, B. Beecher, C.F. Morris, L.C. Hannah, M.J. Giroux, Seed-specific expression of the wheat puroindoline genes improves maize wet milling yields, Plant Biotech. J. 7 (2009)733-743.

[27]S. Gasparis, W. Orczyk, W. Zalewski, A. Nadolska-Orczyk, The RNA-mediated silencing of one of the Pin genes in allohexaploid wheat simultaneously decreases the expression of the other, and increases grain hardness, J. Exp. Bot. 62. (2011) 4025-4036.

[28]A. Pauly, B.Pareyt, E. Fierens, J.A. Delcour,Wheat (Triticumaestivum L. and T. turgidum L. ssp. durum) kernel hardness: I. Current view on the role of puroindolines and polar lipids,Compr. Rev. Food Sci. Food Safety 12 (2013) 413-426.

[29]L. Feiz, H.W. Wanjugi, C.W. Melnyk, I. Altosaar, J.M. Martin, M.J. Giroux,Puroindolines co-localize to the starch granule surface and increase seed bound polar lipid content, J. Cereal Sci. 50 (2009) 91-98.

[30]S.M. Finnie, R. Jeannotte, C.F. Morris, J.M. Faubion,Variation in polar lipid composition among near-isogenic wheat lines possessing different puroindoline haplotypes, J. Cereal Sci. 51 (2010)66-72.

[31]K.H. Kim, L. Feiz, J.M Martin, M. Giroux,Puroindolines are associated with decreased polar lipid breakdown during wheat seed development, J. Cereal Sci. 56(2012)142-146.

[32]L. Dubreil, J.P. Compoint, D. Marion,Interaction of puroindolines with wheat flour polar lipids determines their foaming properties, J. Agric. Food Chem. 45 (1997)108-116. 
[33]S.C. Biswas, D. Marion,Interaction between puroindolines and the major polar lipids of wheat seed endosperm at the air-water interface, Colloid Surfaces B. 53 (2006) 167-174.

[34]C. Bottier, J. Géan, B. Desbat, A. Renault, D. Marion, V. Vié,Structure and orientation into wheat galactolipid monolayers, Langmuir 24 (2008) 10901-10909.

[35]S. Kasas, G. Longo, G. Dietler, Mechanical properties of biological specimens explored by atomic force microscopy, J. Phys. D- Appl. Phys. 46( 2013)133001.

[36]N.E. Kurland, Z. Drira, V.K.Yadavalli, Measurement of nanomechanical properties of biomolecules using atomic force microscopy,Micron 43 (2012)116128.

[37]L. Scudiero, C.F. Morris, Filed emission scanning electron and atomic force microscopy, and Raman and X-ray photoelectron spectroscopy characterization of near-isogenic soft and hard wheat kernels and corresponding flours, J. Cereal Sci. 52 (2010)136-142.

[38]E. Chichti, M. George, J.Y. Delenne, F. Radjai, V. Lullien-Pellerin,Nanomechanical properties of starch and gluten biopolymers from atomic force microscopy,Eur. Polymer J. 49 (2013)3788-3795.

[39]V. Greffeuille, J. Abecassis, M. Rousset, F.X. Oury, A. Faye, C. Bar L'Helgouac'h, V. Lullien-Pellerin,Grain characterization and milling behavior of near-isogenic lines differing by hardness,Theor. Appl. Genetics 114 (2006) 1-12.

[40]M. Akbari, P. Wenzl, V. Caig, J. Carling, L. Xia, S. Yang, G. Uszynski, V. Mohler, A.Lehmensiek, H. Kuchel, M.J. Hayde, N. Howes, P. Sharp, P. Vaughan, B. Rathmell, E. Huttner, A. Kilian, Diversity arrays technology (DART) for high- 
throughput profiling of the hexaploid wheat genome, Theor. Appl. Genetics 113 (2006)1409-1420.

[41]AACC Method 39-70A,in: Approved methods of analysis, $10^{\text {th }}$ Edition,American Association of Cereal Chemists, 2000, The Association, St Paul, Minnesota.

[42]R.Moss, N.L. Stenvert, K. Kingswood, G. Pointing, The relationship between wheat microstructure and flour milling, Scan Electron Micros. III (1980) 613-620.

[43]K.M. Turnbull, D. Marion, T. Gaborit, R. Appels, S. Rahman,Early expression of grain hardness in the developing wheat endosperm, Planta 216 (2003) 699-706.

[44] L. Xia,H. Geng, X. Chen, Z. He, M. Lillemo, C.F. Morris,Silencing of puroindolinea alters the kernel texture in transgenic bread wheat, J. Cereal Sci. 47 (2008)331-338.

[45]G.M. Glenn, R.K. Johnston,Mechanical properties of starch, protein and endosperm and their relationship to hardness in wheat, Food Struct. 11 (1992)187199.

[46]P.J. Burnett, D.S. Rickerby, The relationship between hardness and scratch adhesion, Thin Solid Films 154 (1987) 403-416.

[47]S.J. Bull, D.S. Rickerby, New developments in the modelling of the hardness and scratch adhesion of thin films, Surf. Coat Tech. 42 (1990)149-164.

[48]B. Jonsson, S. Hogmark, Hardness measurements of thin films, Thin Solid Films. 114 (1984) 257-269. 
[49]L.M. Grant, F. Tiberg, Normal and lateral forces between lipid covered solids in solution: correlation with layer packing and structure,Biophys. J. 82(2002)13731385.

[50]A.M. Trunfio-Sfarghiu, Y. Berthier, M.H. Meurisse, J.P. Rieu,Role of nanomechanical properties in the tribological performance of phospholipid biomimetic surfaces,Langmuir. 24 (2008) 8765-8771.

[51] H.F. Darlington, L. Tecsi, N. Harris, D.L. Griggs, I.C. Cantrell, P.R. Shewry,Starch granule associated proteins in barley and wheat, J. Cereal Sci. 32:(2000)21-29.

[52]L.A. Clifton, M.D. Lad, R.J.Green, R.A. Frazier,Single amino acid substitutions in puroindoline-b mutants influence lipid binding properties,Biochem.46 (2007)2260-2266.

[53]M.J. Giroux, C.F. Morris,A glycine to serine change in puroindoline $b$ is associated with wheat grain hardness and low levels of starch-surface friabilin, Theor. Appl. Genetics 95(1997)857-864.

[54]A.C. Hogg, T.Sripo, B. Beecher, J.M. Martin, M.J. Giroux, Wheat puroindolines interact to form friabilin and control grain hardness, TheorAppl Genetics108 (2004)1089-1097.

[55] L. Gazza, F. Taddei, M. Corbellini, P. Cacciatori, N.E. Pogna,Genetic and environmental factors affecting grain texture in common wheat, J. Cereal Sci. 47 (2008) 52-58.

[56]A. Pauly,B. Pareyt, N. De Brier, J.A.Delcour,Incubation of isolated starch with proteolytic or lipolytic enzymes and different extraction media reveals a tight 
interaction between puroindolines and lipids at its granule surface, Cereal Chem. $91(2014) 240-246$. 


\section{Figure Captions}

Figure 1: ESEM images of soft endosperm from Pina-Dla/Pinb-Dla NIL (A) or hard endosperm from Pina-Dla/Pinb-D1b NIL(B) grain sections. Topographic images of the same soft (C) or hard (D) grains but different area obtained with AFM. White arrows in Cindicate the dislodged starch granules commonly observed in soft endosperm whereas black arrows in D indicate cut starch granules, which occurred when hard wheat grains were sectioned with the cryotome. Example of a selected AFM abrasion area corresponding to a small starch granule surface is shown in $\mathrm{E}$ (dotted square) and $\mathrm{F}$ (lower scale). The grey levelbar scale shows the relative height of the explored area.

Figure 2: Example of normalized depth $z_{\text {norm }}$ progression as a function of AFM abrasive scan numbers $\mathrm{N}$ for two distinct (A, B) abraded areas displaying contrasted behavior and observed in endosperm from hard wheat NIL (Pina-D1a/Pinb-D1b genotype). Different line styles and colors are used to point out changes in the fitting curve slope $\alpha$ corresponding to distinct type of encountered material along endosperm abrasion: dashed line for the fitting curve of the softer material (protein) and dotted line for the harder material (starch).

Figure 3: Hardness values obtained for the easily abraded protein material (circles) and the harder starch material (diamonds) encountered along endosperm abrasion from hard (empty symbols) and soft (full symbols) wheat NIL. Already determined hardness mean values and relative errors of pure extracted polymers [38], starch and gluten, were marked with continuous (mean values) and dotted lines (relative errors) respectively. 
Figure 4:A. Changes in the normalized depth $\mathrm{z}_{\text {norm }}$ as a function of the abrasive scan numbers $\mathrm{N}$ for the particular behavior only observed in soft wheat NIL. The distinct removed polymers were discriminated through the different fitting curve slopes $\alpha$ (dashed line for protein and dotted line for starch) as in Fig. 2. The non-abrasive step corresponding to AFM tip slipping is represented by triangles. Picture inserts correspond to the difference between AFM images taken before and after several tip abrasive scans: from left to right, in the protein matrix $(\mathrm{N}=5)$, at the interface $(\mathrm{N}=27)$ and in starch $(\mathrm{N}=6)$.

B. Changes in the lateral friction force $\mathrm{F}_{\mathrm{T}}$ related to the normal applied force $\mathrm{F}_{\mathrm{N}}(+)$ as a function of the abrasive scan number $\mathrm{N}$ for the particular behavior only observed for one part of the explored starch granule surface in soft wheat NIL. Comparison with measured $\mathrm{F}_{\mathrm{T}} / \mathrm{F}_{\mathrm{N}}$ ratio along $\mathrm{AFM}$ imaging of the endosperm topography was reported to point out non-abrasive conditions.

Figure 1 


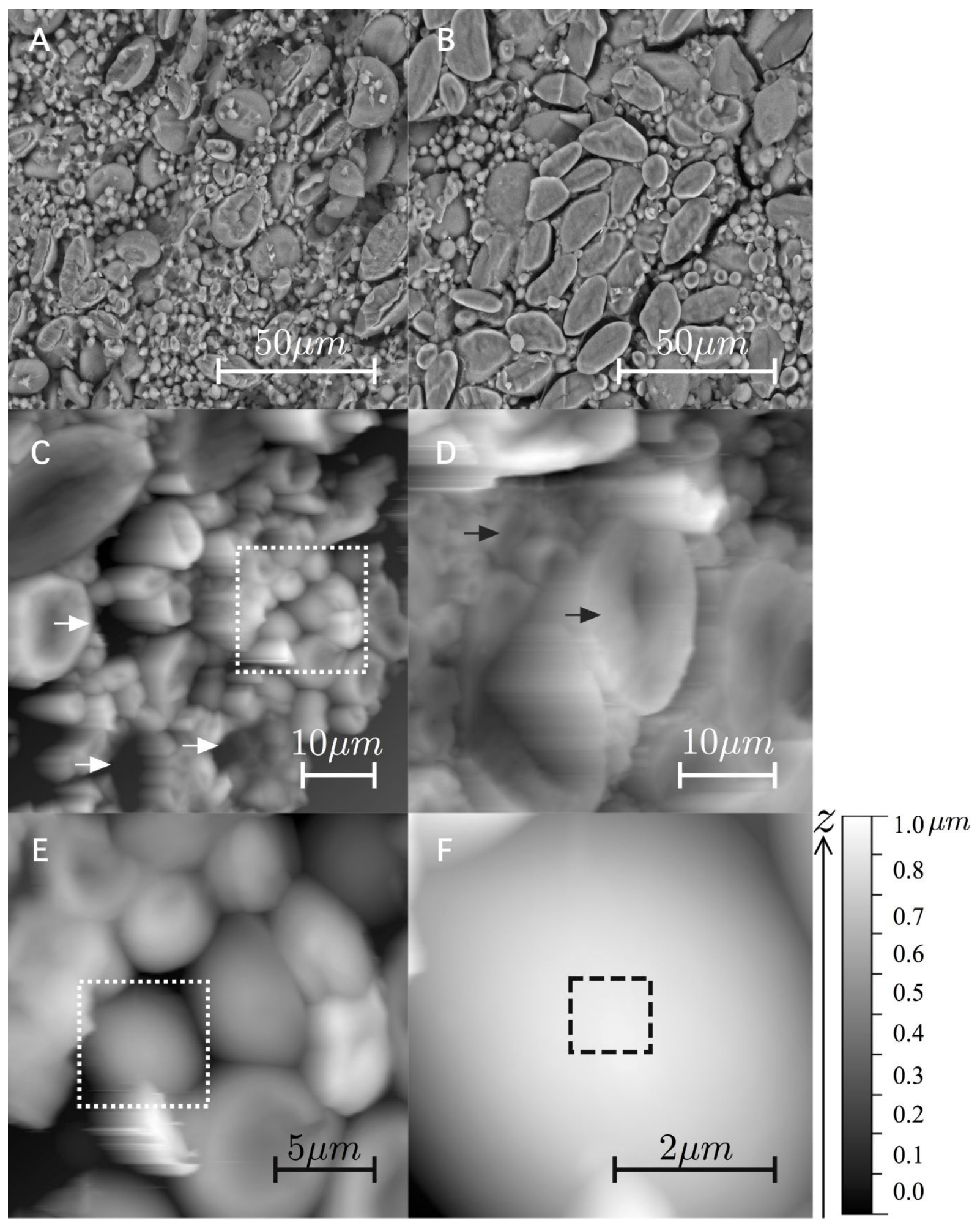

Fig. 1 

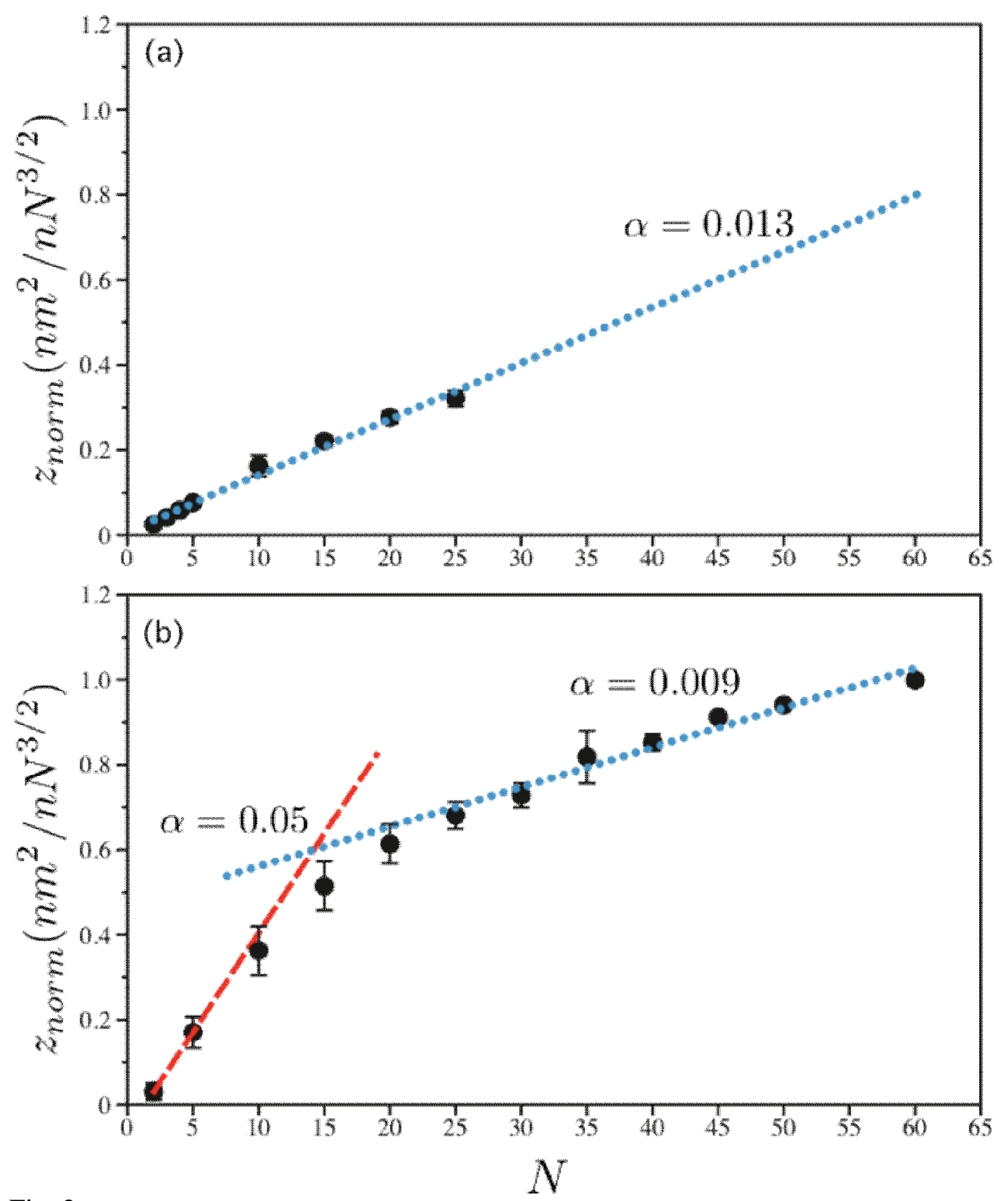

Fig. 2 


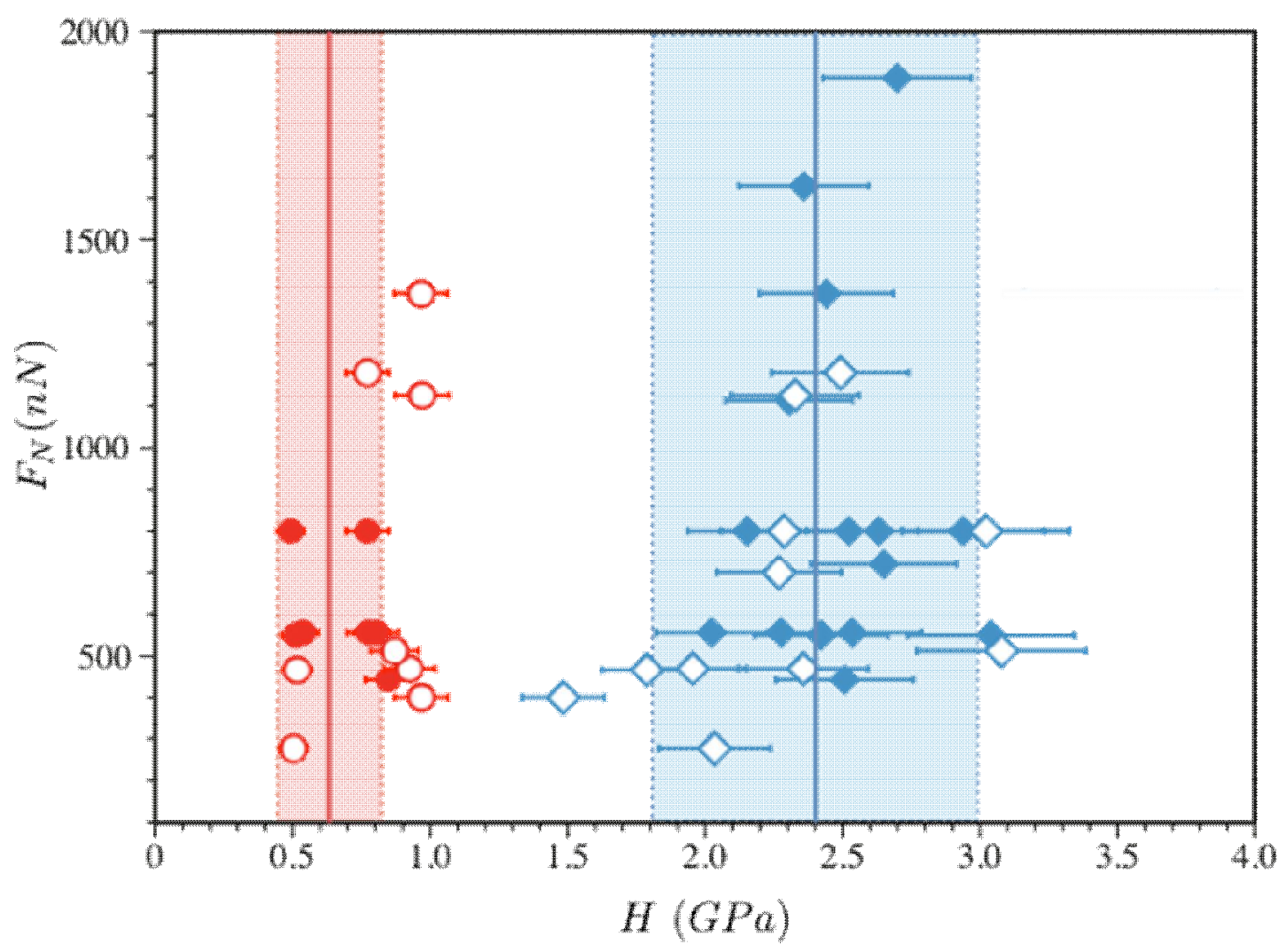

Fig. 3 

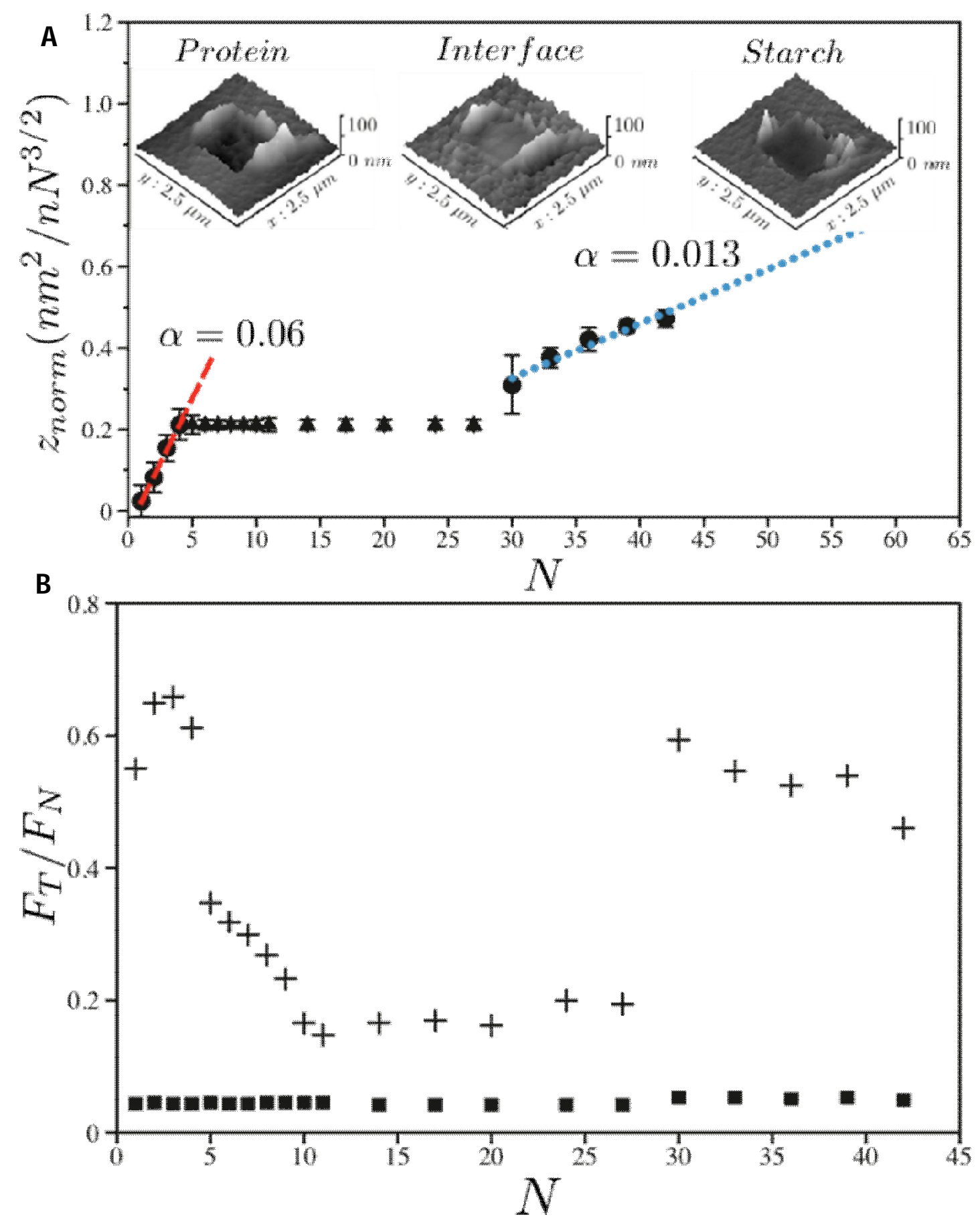

Fig. 4

Table 1.Hardness values for protein and starch obtained from soft and hard wheat grain sections and comparison with data obtainedfrom tablets made of pure polymers using similar AFM abrasion scratching assays [38]. Different letters indicate statistically distinct values. 


\begin{tabular}{|l|l|l|}
\hline & Starch Hardness (MPa) & Protein Hardness (MPa) \\
\hline Polymer Tablets & $2400 \pm 600^{\mathrm{a}}$ & $640 \pm 170^{\mathrm{b}}$ \\
\hline Hard (Pina-Dla/Pinb-Dlb) & $2370 \pm 600^{\mathrm{a}}$ & $811 \pm 200^{\mathrm{b}}$ \\
\hline Soft (Pina-Dla/Pinb-Dla) & $2532 \pm 300^{\mathrm{a}}$ & $677 \pm 150^{\mathrm{b}}$ \\
\hline
\end{tabular}

